\title{
Hemifacial Spasms Provoked by Ipsilateral Gaze
}

\author{
Dimitri Renard $^{\mathrm{a}}$ Luc Jeanjean $^{\mathrm{b}}$ Salem Ghanem ${ }^{\mathrm{c}}$ Giovanni Castelnovo ${ }^{\mathrm{a}}$ Pierre Labauge $^{\mathrm{a}}$ \\ Departments of ${ }^{a}$ Neurology, ${ }^{b}$ Ophthalmology, and ${ }^{\mathrm{c}}$ Radiology, CHU Nîmes, Hôpital Caremeau, Nîmes, France
}

Dear Sir,

A 78-year-old man with diabetes mellitus, hypercholesterolemia, arterial hypertension, and obstructive sleep apnea syndrome as cardiovascular risk factors and a history of transient conjugate right-sided gaze palsy (confirmed by a neuro-ophthalmologist) 1 year ago presented with paroxysmal right-sided facial contractions. Clinical examination showed right (inferior dominant) hemifacial spasms provoked by lateral gaze (on both pursuit and saccade) to the right (online supplementary video 1 , www.karger.com/doi/10.1159/000287472). Oculomotricity testing was strictly normal. Brain MRI showed periventricular leukoencephalopathy and small multifocal $\mathrm{T}_{2}$-hyperintensities in the brainstem compatible with ischemic microangiopathy. 3D CISS MRI sequences confirmed bilateral microangiopathic changes at the pontomesencephalic junction and the lower pons (corresponding to the location of the center implicated in lateral gaze), in absence of abnormalities along the extra-axial part of the abducens and facial nerves (fig. 1). Since our patient had an episode of conjugate gaze palsy (and not isolated abduction palsy), synkinesis was probably related to injury of the brainstem structures involved in lateral gaze (rather than related to intraor extra-axial abducens nerve injury) inducing aberrant regeneration to the most nearby axons (i.e. the inferior part) of the facial nucleus or fasciculus. This lateral gaze center contains (1) excitatory burst neurons in the paramedian pontine reticular formation responsible for ipsilateral horizontal saccade and (2) gaze centers playing a role in ipsilateral horizontal smooth pursuit. Both gaze centers project to the ipsilateral abducens nucleus which controls both abducens motor neurons (responsible for ipsilateral eye abduction) and internuclear neurons projecting via the medial lateral fasciculus to contact the medial rectus subgroup of the contralateral oculomotor neurons (responsible for contralateral eye adduction).

Synkinesis is most common between different parts of the same nerve. The facial nerve is the most frequently involved cranial nerve, although synkinesis in other cranial nerves has been described (e.g. oculomotor nerve) $[1,2]$. Only a few cases of synkinesis between two different cranial nerves have been reported (e.g. facial-trigeminal, trigeminal-oculomotor, trigeminal-abducens, abducens-trigeminal, facialoculomotor, and oculomotor-abducens synkinesis) [3-12]. Since hemifacial contractions were provoked by both smooth pursuit and saccade to the right side in our patient, the primary lesion was probably in the abducens nucleus itself. Synkinesis between the abducens and facial nucleus or nerve, like in our patient, has never been described earlier. In our patient, injury of the abducens nucleus was probably ischemic in origin due to microangiopathy. Pathophysiologically, aberrant regenera-

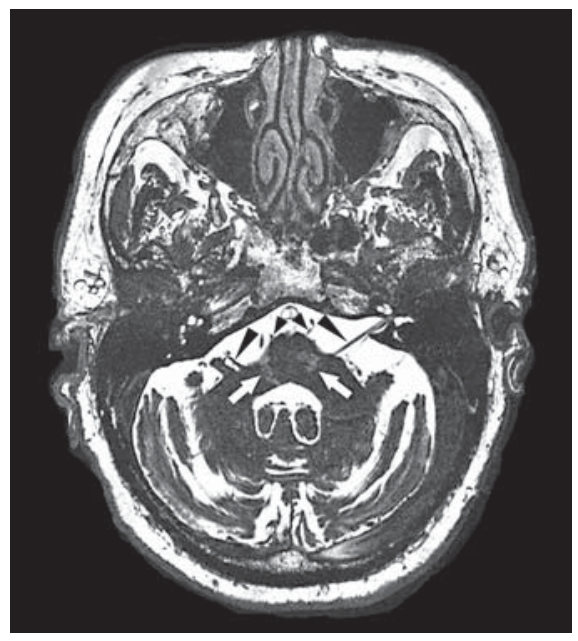

Fig. 1. 3D CISS MRI sequences showing bilateral ischemic microangiopathic $\mathrm{T}_{2}$ hyperintensities (arrows) at the pontomesencephalic junction and the lower pons, in absence of abnormalities along the extraaxial abducens (small arrowheads) and facial (large arrowheads) nerves.

tion of injured axons to nearby uninvolved axons is the most probable mechanism in synkinesis. Another theory suggests that ephaptic transmission occurs between injured, poorly myelinated, axons and adjacent normal axons, thereby creating an artificial synapse between the nerves.

\section{KARGER}

Fax +41613061234 E-Mail karger@karger.ch www.karger.com
Dimitri Renard

Department of Neurology, CHU Nîmes, Hôpital Caremeau

Place du Pr Debré, FR-30029 Nîmes Cedex 4 (France)

Tel. +33466 6832 61, Fax +33466684016

E-Mail dimitrirenard@hotmail.com 


\section{References}

1 Sibony PA, Lessell S, Gittinger JW Jr: Acquired oculomotor synkinesis. Surv Ophthalmol 1984;28:382-390.

-2 Weber ED, Newman SA: Aberrant regeneration of the oculomotor nerve: implications for neurosurgeons. Neurosurg Focus 2007; 23:E14.

- 3 McGovern ST, Crompton JL, Ingham PN: Trigemino-abducens synkinesis: an unusual case of aberrant regeneration. Aust NZ J Ophthalmol 1986;14:275-279.

4 Burroughs JR, Anderson RL, Elliot RL: Correction of congenital blepharoptosis in oculomotor-abducens synkinesis. Ophthal Plast Reconstr Surg 2006;22:64-65.
5 Ghodasra DH, Nallasamy S, Binenbaum G: Congenital trigemino-abducens synkinesis in a neonate. J AAPOS 2009;13:417-418.

6 Khan AO, Al-Hommaidi A, Al-Turkmani S: Familial ptotic lid elevation during ipsilateral abduction. J AAPOS 2004;8:571-575.

7 Rubin DI, Matsumoto JY, Suarez GA, Auger RG: Facial trigeminal synkinesis associated with a trigeminal schwannoma. Neurology 1999;11:635-637.
8 Wutthiphan S, Poonyathalang A: Abducensoculomotor synkinesis following acquired sixth nerve palsy. J Pediatr Opthalmol Strabismus 2002;39:362-364.

9 Lemke C, el Bably I: Synkinesis between facial nerve and oculomotor nerve. A case report. Ann Anat 1998;180:339-342.

10 Shulman LM, Gallo BV, Weiner WJ: Acquired abducens-trigeminal synkinesis. Neurology 1998;50:1507-1508.

-11 Nelson SK, Kline LB: Acquired trigeminoabducens synkinesis. J Clin Neuroophthalmol 1990;10:111-114

12 Jordan DR, Miller DG, Anderson RL: Acquired oculomotor-abducens synkinesis. Can J Ophthalmol 1990;25:148-151. 